\title{
Inappropriate Antibiotic Allergy Documentation in Medical Files: A Qualitative Study on Family Physicians' and Pharmacists' Experiences
}

\author{
Ada Yu, DO, Grant Family Medicine \\ Michael E. Johansen, MD, MS, Associate Editor \\ Ann Fam Med 2020;18(4):iii. https://doi.org/10.1370/afm.2578.
}

The Annals of Family Medicine encourages readers to develop a learning community to improve health care and health through enhanced primary care. Participate by conducting a journal club. We encourage diverse participants to think critically about important issues affecting primary care and act on those discussions. ${ }^{1}$

\section{HOW IT WORKS}

In each issue, the Annals selects an article and provides discussion tips and questions. Post a summary of your conversation in our online discussion. (Open the article and click on the eLetters tab, and submit a comment.) Discussion questions and information are online at: https://www.AnnFamMed.org/content/AJC.

\section{CURRENT SELECTION}

\section{Article for Discussion}

De Clercq K, Cals JWL, de Bont EGPM. Inappropriate antibiotic allergy documentation in health records: a qualitative study on family physicians' and pharmacists' experiences. Ann Fam Med. 2020;18(4):326333.

\section{Discussion Tips}

Qualitative research offers an opportunity to gain a richer understanding of why things are happening. As clinicians, we have pondered similar questions the researchers asked family physicians and pharmacists about antibiotic allergies. Consider how you deal with patient-reported allergies as a physician. How granular are your system's reporting mechanisms? Is your electronic medical record connected to the pharmacist's medical record?

\section{Discussion Questions}

- What question is asked by this study and why does it matter?

- How does this study advance beyond previous research and clinical practice on this topic?

- What is a focus group? How strong is this study design for answering the question? What are weaknesses of this type of study?

o What is saturation?

- What methods did the authors use to minimize bias in the conduct and analysis of the study?

- To what degree can the findings be accounted for by: 1. How participants were selected or excluded?

2. How the findings were interpreted?

-What are the main study findings?

o How did you feel about the grouping of quotes into 3 main categories?

o Did the highlighted quotes support the analysis? Did you identify with any of the quotes?

o What is a fish-bone diagram? Does it help you understand what is going on here?

- How comparable is the study sample to your location? What is your judgment about the transportability of the findings?

o Do you relate to the focus group participants?

- What contextual factors are important for interpreting the findings?

o What is an allergy registration?

- How might this study change your practice? Policy? Education? Research?

- What challenges do you see with trying to improve the reporting of antibiotic allergies?

- What are the next steps in interpreting or applying the findings?

- What researchable questions remain?

\section{References}

1. Stange KC, Miller WL, McLellan LA, et al. Annals Journal Club: It's time to get RADICAL. Ann Fam Med. 2006;4(3):196-197. https:// AnnFamMed.org/cgi/content/full/4/3/196. 